\title{
Assessment of the Mutational Status of NSCLC Using Hypermetabolic Circulating Tumor Cells
}

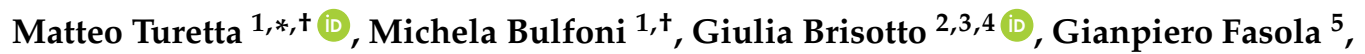 \\ Andrea Zanello ${ }^{1}$, Eva Biscontin ${ }^{2}$, Laura Mariuzzi ${ }^{1,5}$, Agostino Steffan ${ }^{2}$, Carla Di Loreto ${ }^{1,5}$, \\ Daniela Cesselli ${ }^{1,5}$ and Fabio Del Ben ${ }^{1,2, *(1 D)}$ \\ 1 Department of Medicine, University of Udine, P.le Kolbe 4, 33100 Udine, Italy; \\ michela.bulfoni@uniud.it (M.B.); zanello.andrea@spes.uniud.it (A.Z.); laura.mariuzzi@uniud.it (L.M.); \\ carla.diloreto@uniud.it (C.D.L.); daniela.cesselli@uniud.it (D.C.) \\ 2 Immunopathology and Cancer Biomarkers, C.R.O. Aviano National Cancer Institute IRCCS, via F. Gallini 2, \\ 33081 Aviano (PN), Italy; gbrisotto@cro.it (G.B.); eva.biscontin@gmail.com (E.B.); asteffan@cro.it (A.S.) \\ 3 IOV-IRCCS, Immunology and Molecular Oncology Unit, V. Gattamelata 64, 35128 Padova, Italy \\ 4 DISCOG, University of Padova, V. Giustiniani 2, 35128 Padova, Italy \\ 5 Udine Academic Hospital, P.le Santa Maria della Misericordia 15, 33100 Udine, Italy; \\ gianpiero.fasola@asuiud.sanita.fvg.it \\ * Correspondence: matteo.turetta@uniud.it (M.T.); fabio.delben@cro.it (F.D.B.) \\ + These authors contributed equally to the work.
}

Received: 28 May 2018; Accepted: 10 August 2018; Published: 14 August 2018

\begin{abstract}
Molecular characterization is currently a key step in NSCLC therapy selection. Circulating tumor cells (CTC) are excellent candidates for downstream analysis, but technology is still lagging behind. In this work, we show that the mutational status of NSCLC can be assessed on hypermetabolic CTC, detected by their increased glucose uptake. We validated the method in 30 Stage IV NSCLC patients: peripheral blood samples were incubated with a fluorescent glucose analog (2-NBDG) and analyzed by flow cytometry. Cells with the highest glucose uptake were sorted out. EGFR and KRAS mutations were detected by ddPCR. In sorted cells, mutated DNA was found in $85 \%$ of patients, finding an exact match with primary tumor in $70 \%$ of cases. Interestingly, in two patients multiple KRAS mutations were detected. Two patients displayed different mutations with respect to the primary tumor, and in two out of the four patients with a wild type primary tumor, new mutations were highlighted: EGFR p.746_750del and KRAS p.G12V. Hypermetabolic CTC can be enriched without the need of dedicated equipment and their mutational status can successfully be assessed by ddPCR. Finally, the finding of new mutations supports the possibility of probing tumor heterogeneity.
\end{abstract}

Keywords: CTC; metabolism; glucose uptake; non-small cell lung cancer; liquid biopsy

\section{Introduction}

Cancer is a leading cause of morbidity and mortality worldwide [1]. In the last years, advances in drug development enabled the employment of targeted therapies using drugs inhibiting specific pathways of critical importance for the survival of cancer cells. The growing number of treatment options, their effectiveness in a limited subset of patients, and their elevated costs, pressed the need to predict the individual response to therapy before starting the treatment. The so-called "predictive biomarkers" are therefore of critical importance in assisting clinicians in the selection of the most effective therapy. Non-Small Cell Lung Cancer (NSCLC) is one of the most prevalent and lethal cancer types [2]. Recently, multiple targeted treatments were made available for NSCLC, targeting EGFR, ALK, or BRAF mutations [2]. Current clinical practice includes the characterization 
of molecular subtypes of NSCLC, performed on biopsy specimens, obtained with a core biopsy. Recent advances made it possible to identify some mutations (e.g., EGFR mutations) in circulating tumor DNA, obtained from peripheral blood [3]. The sampling of tumor material from body fluids (mainly peripheral blood, but also urine, cerebrospinal fluid, tears, and saliva) is commonly addressed as a "liquid biopsy", and it targets circulating tumor cells (CTC), circulating tumor DNA (ctDNA) or RNA, and exosomes [4]. Being minimally invasive, a liquid biopsy can be performed multiple times during the course of treatment, providing timely feedback on disease evolution, including the appearance of drug-resistances, thus enabling a rapid adjustment of therapy [4]. The quantification of CTC number and ctDNA level in the peripheral blood already proved to be prognostic in other cancer types, predicting disease progression several months in advance with respect to imaging [5-8], and providing useful information to guide targeted therapy $[9,10]$. Beside mere enumeration, CTC can be isolated and molecularly characterized to retrieve information on their mutational status, driving decision in targeted therapy selection, as recently proven in metastatic castration-resistant prostate cancer [9].

However, while some ctDNA technologies already reached FDA-approval to guide therapy, CTC technology is still lagging behind. CTC are cancer cells present in the peripheral blood of most solid tumors. They are rare (typically $1-100 / \mathrm{mL}$ ), highly heterogeneous cells, and there is no clear consensus on their definition [11]. FDA has approved the quantification of CTC detected by CellSearch as a prognostic test for breast, colorectal, and prostate metastatic cancer. This test recognizes CTC as nucleated DAPI (4',6-diamidino-2-phenylindole)(+), EpCAM (Epithelial Cell Adhesion Molecule)(+), CK (cytokeratin)(+), CD45(-) cells. However, such definition leads, in the case of NSCLC, to an insufficient sensitivity in CTC detection (approximately 20\%) [12]. Other CTC subsets include CK(-) cells, cells undergoing Epithelial to Mesenchymal transition (EMT), apoptotic CTC; moreover, although there are size-based methods enriching in CTC, evidences showed the existence of CTC with a size comparable to that of white blood cells $[13,14]$. Each subset has been exploited by a different innovative device, with the main downside of an a priori selection of a subtype of CTC. EpCAM-based and size-based technologies are the most widespread. The restriction of validated CTC detection methods to a limited number of solid tumors is penalizing patients with a highly prevalent disease such as NSCLC, in which the antibody cocktail employed by CellSearch and other techniques are insufficient to detect CTC, as demonstrated by the low sensitivity of CellSearch in NSCLC (approximately 20\%) [12] and the absence of NSCLC CTC-specific markers. This most likely happens because in such disease most CTC undergo EMT, therefore losing EpCAM expression, which is mandatory for capturing CTC with the CellSearch system [15]. Other techniques relying, for example, on an EGFR-, HER2-, and EpCAM-dependent enrichment achieved a higher, but still low sensitivity $(29 \%)$, slightly increased $(42 \%)$ in patients harboring tumors with altered EGFR genotype [16]. CTC characterization in NSCLC were found to express genes involved in therapy resistance such as HER3 and MET, highlighting the clinical relevance of such analysis for early detection of drug resistance in therapy monitoring [17]. A different approach, proposed by Dorsey et al., was based on the evaluation of telomerase activity, which is a specific marker of cancer cells in both the epithelial and EMT phenotypes; this study demonstrated the correlation between CTC burden and treatment success [18]. Another work, regarding EpCAM(-) detection of CTC in NSCLC, proposed a pre-enrichment step using hematopoietic cell depletion, followed by a multiparametric fluorescence analysis, comprising pan-cytokeratin, EpCAM, N-cadherin (specific of mesenchymal cells), and CD133 (stem-like marker). The presence of mesenchymal and stem-like cells was associated with a reduced response to platinum therapy [19]. In addition to changes in protein expression and morphology, CTC present functional alterations, summarized in a recent list of hallmarks of cancer, including an altered metabolism, that have been exploited for their detection [20-23]. One of the most well described metabolic alterations is increased glucose uptake in cancer cells, involving the upregulation of GLUT channels [20,24]. This alteration is early-appearing in cancer evolution [25], well-conserved during invasive and metastatic transformation [26], associated with aggressive phenotypes and worse 
prognosis [27-29]. Such increased glucose metabolism is notoriously exploited in the clinical routine by imaging solid tumors with positron-emission tomography [30,31]. The ability to detect both epithelial and mesenchymal phenotypes exploiting their increased uptake of glucose was recently shown by our group in a work on cancer cell lines [32], in which we also hypothesized that such method could have been applied to improve detection of CTC. Here, we report the proof-of-concept of such hypothesis by detecting and harvesting hypermetabolic CTC in the peripheral blood of NSCLC patients.

\section{Results}

\subsection{Feasibility Study}

\subsubsection{Tumor Cells Are Characterized by an Increased Glucose Uptake}

To assess whether tumor cells are characterized by an increased metabolism, with respect to white blood cells (WBC), glucose uptake was evaluates by employing a fluorescent glucose analogue, the 2-(N-(7-Nitrobenz-2-oxa-1,3-diazol-4-yl)Amino)-2-Deossiglucose) (2-NBDG). We measured the glucose uptake of both lung cancer (A549, H1975 and H460) and breast cancer (MCF-7 and MDA-MB231) cell lines, as well as that of WBC. As shown in Figure 1, all cancer cell lines showed comparable values of glucose uptake, which resulted to be, in median, more than 10-fold higher than that of WBCs (Figure 1 and Table 1).
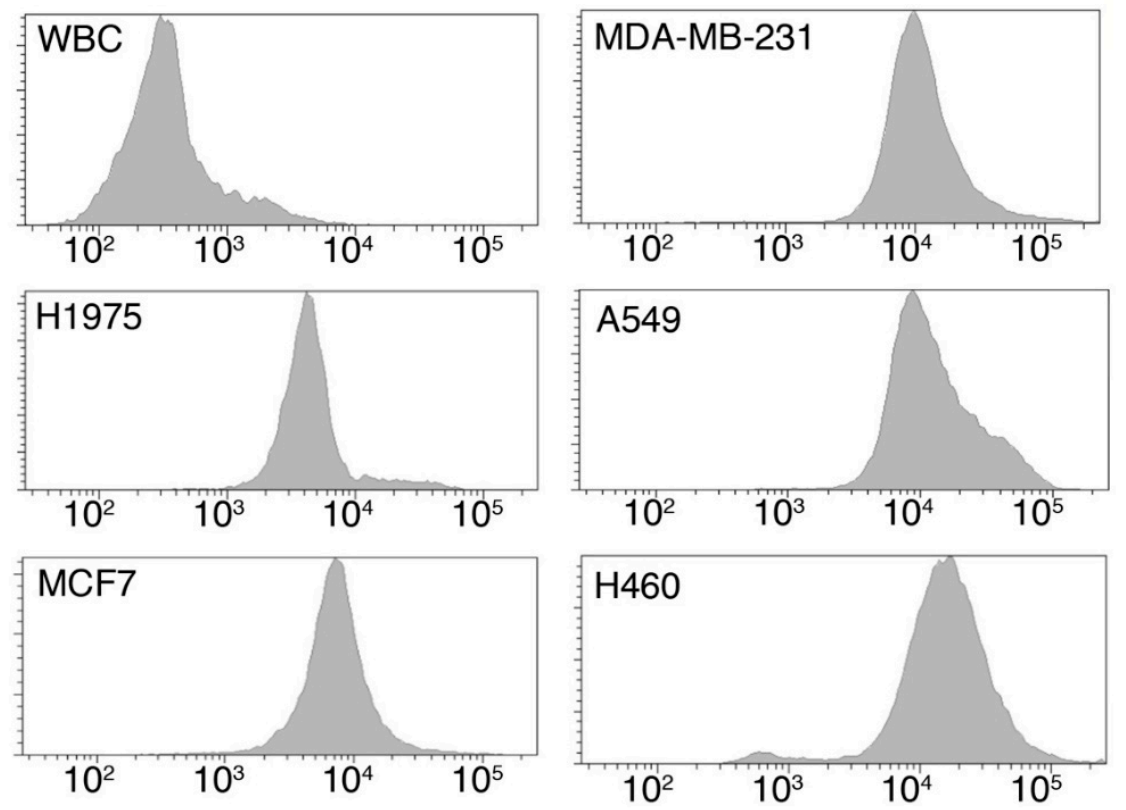

Figure 1. Measurement of glucose uptake by flow cytometry. Representative histograms reporting the 2-NBDG fluorescence of WBCs and of the tested cell lines H1975, MDA-MB-231, MCF7, A549, and $\mathrm{H} 460$.

To evaluate whether the glucose uptake would remain unchanged if cancer cells were mixed with WBCs, MDA-MB-231 as well as H1975 and H460 were mixed with WBCs (Figure 2). Cancer cells were pre-labeled with Hoechst to make them easily and unequivocally distinguishable from WBCs (Figure 2A). The median glucose uptake of Hoechst $(+)$ cancer cells in spike-in samples was, with respect to cancer cells alone, about 1.5- and 2-fold decreased in MDA-MB-231 and H460 cell lines, while an opposite trend was seen for H1935 cells (Figure 2B). Nonetheless, the distribution curves of the glucose uptake of WBC and Hoechst(+) cancer cells in the spike-in samples were always significantly different (Two-sample Kolmogorov-Smirnov test, $p<0.0001$ ), as well as the median intensity of the two populations (Figure 2B). 
Table 1. Uptake of glucose analogue by different cell types. The 2-NBDG uptake is expressed as mean fluorescence intensity and standard deviation (SD). Each cell line and WBC from three different healthy subjects were tested in triplicate. ${ }^{*} p$ value obtained comparing cell lines and WBC by Mann-Whitney test.

\begin{tabular}{cccc}
\hline Cell Type & Origin & Median Fluorescence Intensity (A.U.) & $p$-Value * \\
\hline WBC & Healthy donor & 291 & - \\
H1975 & Lung Cancer & 4758 & 0.0238 \\
MDA-MB-231 & Breast Cancer & 8338 & 0.0043 \\
MCF-7 & Breast Cancer & 6983 & 0.0238 \\
A549 & Lung Cancer & 9977 & 0.0238 \\
H460 & Lung Cancer & 19,764 & 0.0095 \\
\hline
\end{tabular}
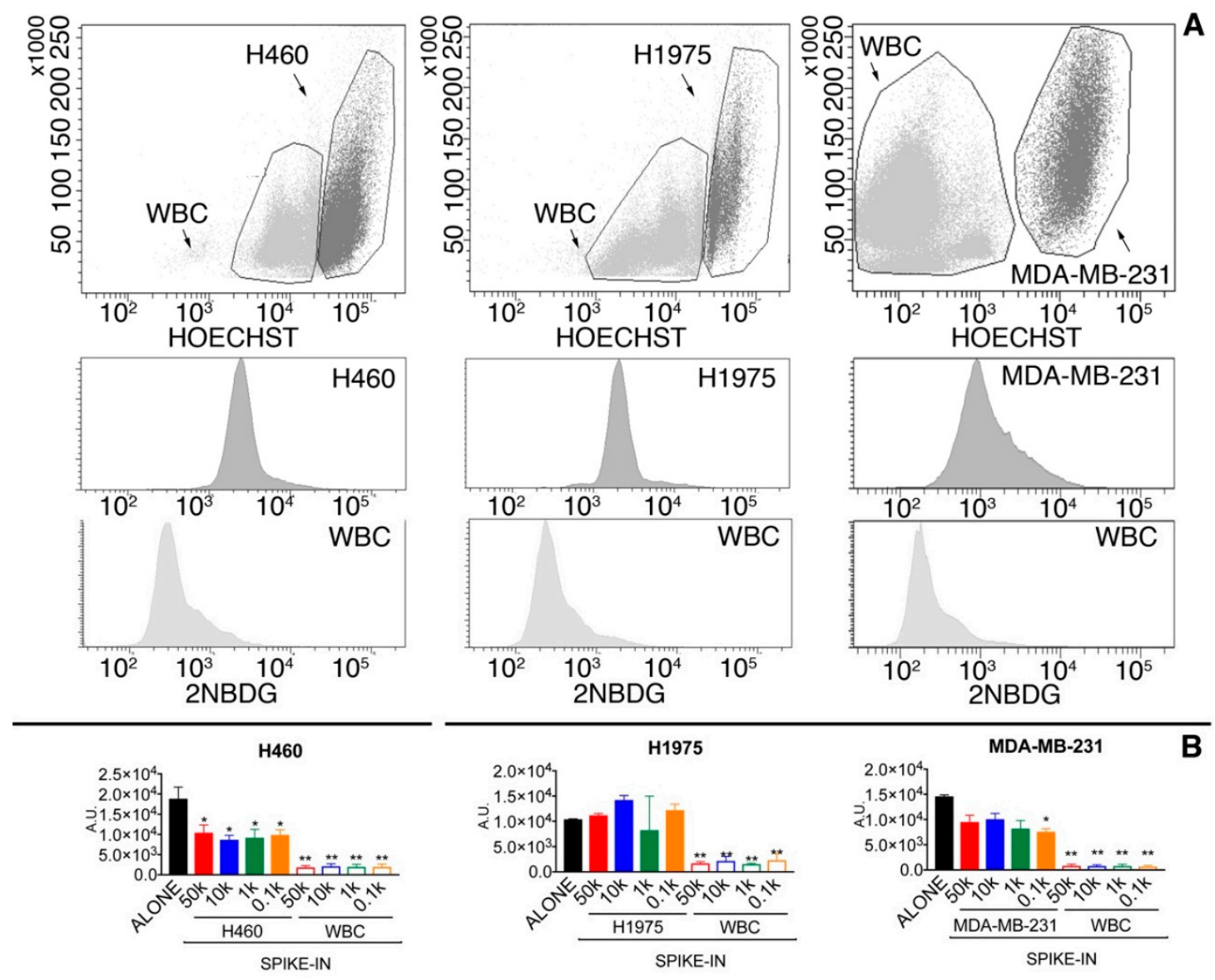

Figure 2. (A) Glucose uptake of tumor cells and WBC in spike-in samples. Representative images of spike-in samples (50,000 cells) of H460, H1975, and MDA-MB-231 in WBC. In the upper panels, SSC/Hoechst dot-plots were used to discriminate tumor cells (Hoechst(+), dark grey) from WBC (Hoechst $(-)$, light grey). In the lower panels are presented the histograms showing the 2-NBDG positivity of tumor cells (middle panels) and WBC (lower panels), respectively; (B) glucose uptake in tumor cells alone and in spike-in samples. Data are presented as median and interquartile range. Black columns indicate the glucose uptake of tumor cells alone. All the other solid columns refer to different spike-in sample in which 50,000 (50k), 10,000 (10k), 1000 (1k), and 100 (0.1k) tumor cells were spiked into peripheral blood samples. The last four columns indicate the glucose uptake of WBC in the 50k, $10 \mathrm{k}, 1 \mathrm{k}$, and $0.1 \mathrm{k}$ spike-in samples. ${ }^{*}, p<0.005$ of tumor cells in spike in sample with respect to cells alone (Kruskal-Wallis test followed by Dunn's post-test). ${ }^{* *}, p<0.05$ of WBC versus the tumor cells of the corresponding spike-in sample (Mann-Whitney test). 
The analysis of the area under the curve (AUC) of the Receiver Operating Characteristic (ROC) curves showed that the glucose-uptake parameter presented an accuracy, in discriminating tumor cells from WBC, of 0.82, 0.96, and 0.96 for MDA-MB-231, H460, and H1975, respectively (Figure 3).
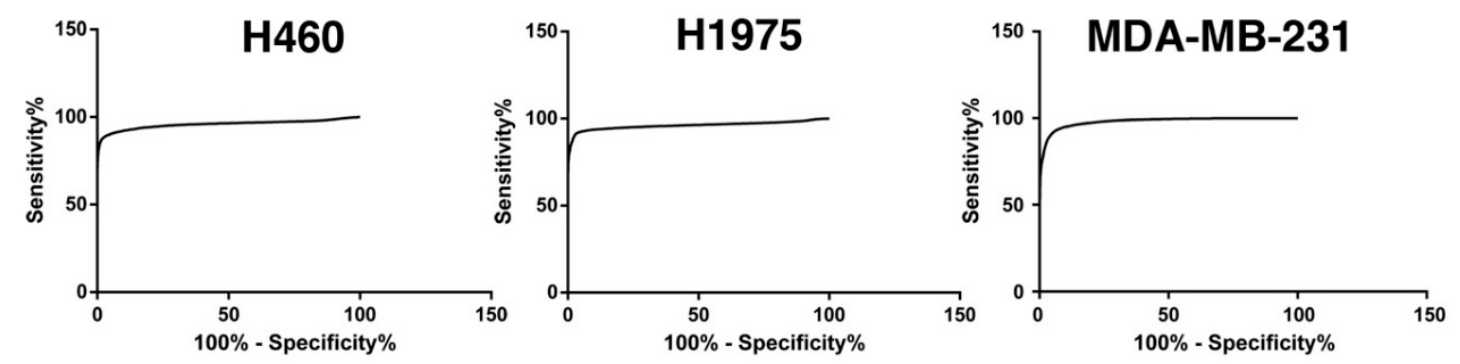

Figure 3. ROC curves obtained analyzing the 2-NBDG positivity of WBC and tumor cells in spike-in samples. See text for more details.

In conclusion, glucose uptake was significantly higher in tumor cell lines with respect to WBC, and this difference remained significant in spike-in samples.

\subsubsection{Glucose Uptake Can Be Used to Recover Tumor Cells from Spike-in Samples}

To establish the ability of the metabolic assay to recover tumor cells from the peripheral

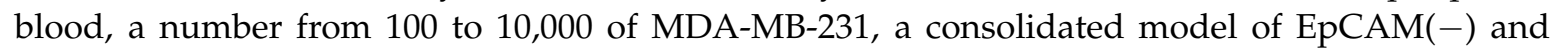
metastasis-competent cancer cells, was spiked into peripheral blood. Only cancer cells were pre-labeled with Hoechst to make them easily and unequivocally distinguishable from WBCs. The spiked sample was processed lysing red blood cells and incubating it with the glucose analogue 2-NBDG.

The number of Hoechst $(+)$ cancer cells present in the sample after liquid handling was, on average, $55 \pm 21 \%$ of the spiked ones, with a linear correlation analysis yielding an R-squared of 0.84 (Figure 4). This number is in line with that obtained by other authors and our group using living cells in spike-in experiments and it can be explained not only by the loss of cells due to the handling procedures, but also by the death of part of the spiked cells by anoikis and immuno-mediated phenomena [33-36].

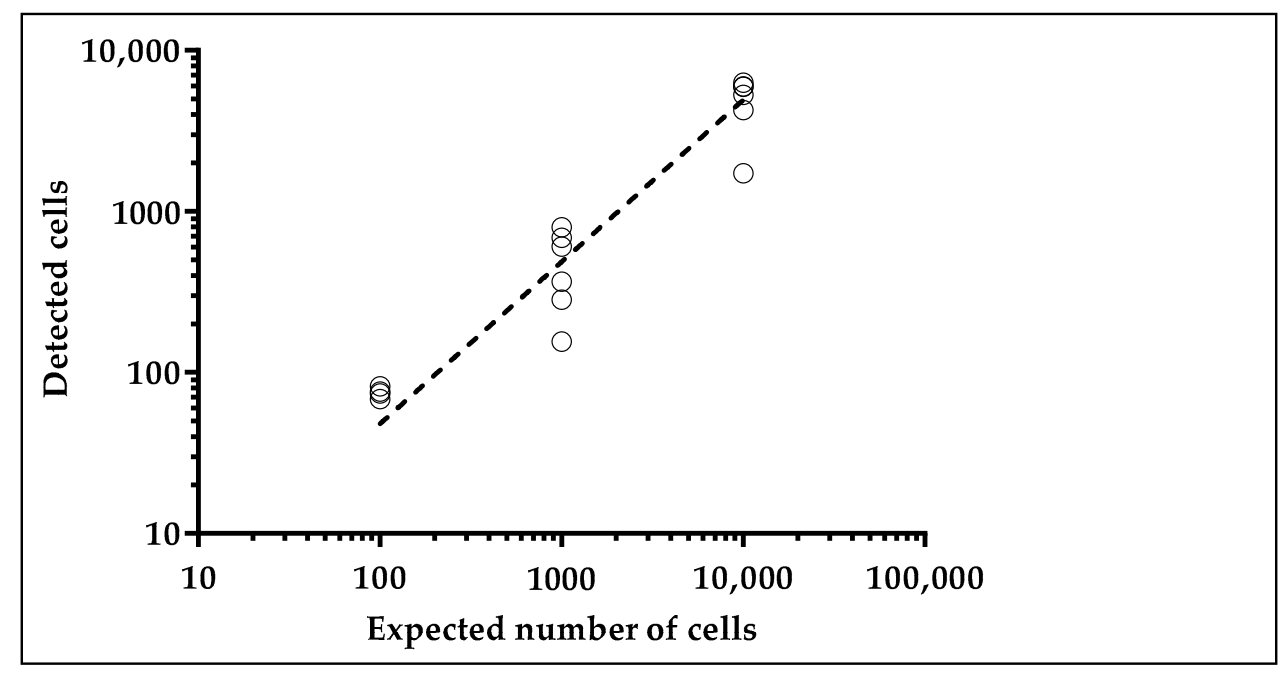

Figure 4. Series of spiking assays with cancer cells pre-labeled with Hoechst. Number of Hoechst positive (detected) cells with respect to the number of spiked ones (expected cells).

To create a consistent gating mask to apply to patient samples in order to recognize the highly metabolically active cells, we chose to test operator-independent thresholds based on the 2-NBDG 
distribution in the WBC population. Specifically, we set the threshold using, as cut-off levels, 3-, 5-, and 7-fold the average intensity of WBCs for 2-NBDG, as well as the 2-NBDG average intensity +2.5 standard deviation. Table 2 and Supplementary Table S1, indicates, for each assayed cut-off level, which fraction of Hoechst(+) cells was indeed recovered and how many contaminating WBC were present. Decreasing the stringency of the selection, the fraction of recovered CTC increased (from $32.1 \%$ to $74.9 \%$ ), as well as the number of contaminating WBC (from 1412 to 9341). Since the "dilution" of CTC could not exceed the sensitivity of the ddPCR in detecting specific mutations $\left(10^{-4}\right)$, we set as cut-off level the average uptake of WBC plus 2.5-fold the standard deviation (named threshold "2.5 SD").

Table 2. Performances of the metabolic assay depending on the selected threshold. The table shows, for each assayed cut-off level used to define cells as 2-NBDG(high), tumor cell recovery, and number of WBC contaminants. Tumor cell recovery was defined as the number of 2-NBDG(high) Hoechst(+) cancer cells/total number of Hoechst $(+)$ cancer cells $\times 100$. WBC contaminants were defined as the number of white blood cells present in the 2-NBDG(high) population. Cut-off levels were defined as 3-, 5-, and 7-fold the average intensity of the WBC for 2-NBDG as well the average 2-NBDG fluorescence intensity +2.5 -fold its standard deviation (gate “ $2.5 \mathrm{SD}^{\prime}$ ). Data are presented as average values between all the analyzed spike-in samples.

\begin{tabular}{ccc}
\hline Cut-Off Level & Tumor Cell Recovery & WBC Contaminants \\
\hline 3-fold WBC average & $74.9 \%$ & 9341 \\
5-fold WBC average & $46.5 \%$ & 3052 \\
7-fold WBC average & $32.1 \%$ & 1412 \\
WBC average + 2.5-folds SD & $59.8 \%$ & 4473 \\
\hline
\end{tabular}

Using as the cut-off level the gate "2.5 SD", the fraction of 2-NBDG(high) cancer cells displayed a good linearity with the total number of cancer cells, being $\mathrm{R}^{2}=0.95$ (Figure 5).

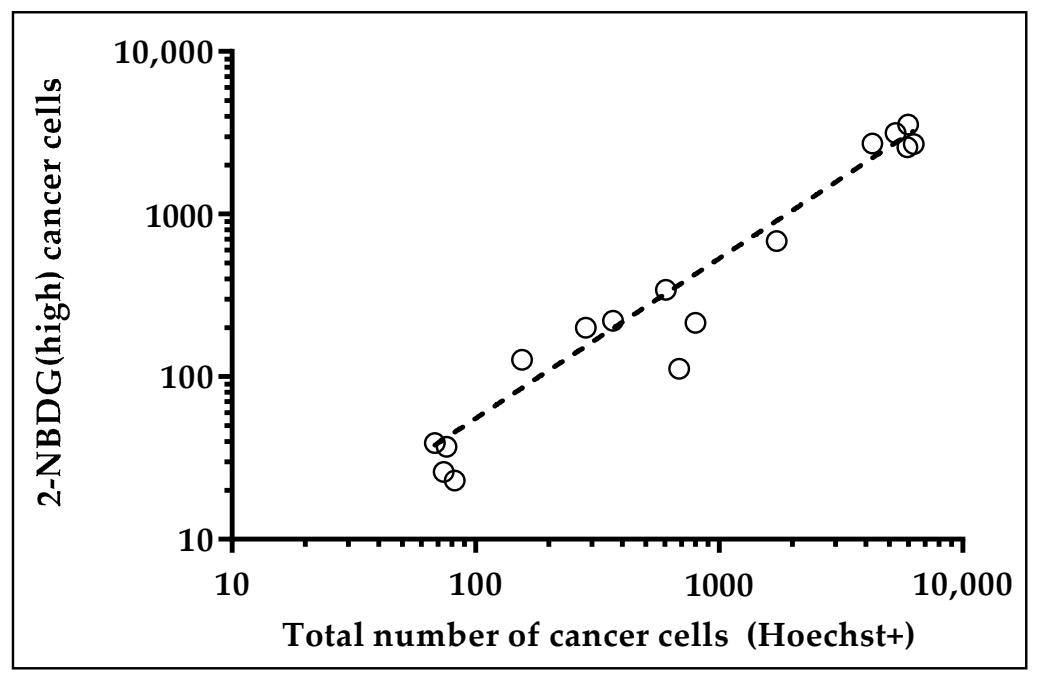

Figure 5. Cancer cells positive for 2-NBDG(+) plotted against the total number of cancer cells (Hoechst(+)) using as the cut-off level "2.5 SD".

\subsubsection{Highly Metabolic Cells Sorted from Spike-in Samples by FACS Are Suitable for ddPCR Analysis}

To establish whether the designed CTC enrichment strategy, based on sorting putative CTC on the basis of their metabolism, would allow us to detect by ddPCR specific gene mutations, 1000, 500, 100, and $10 \mathrm{H} 1975$ cells, harboring the EGFR p.L858R mutation, were spiked in $1 \mathrm{~mL}$ of peripheral blood. The presence of the mutation was indeed demonstrated in all the samples sorted adopting the gate "2.5 SD" (Figure 6). As expected on the basis of the recovery rate of living tumor cells from 
spike-in samples, the number of mutated copies was, on average, $52.2 \%$ of the expected ones, although with variable efficiencies $(55.4 \%, 39.2 \%, 84 \%$, and 38\% for 1000, 500, 100, and 10 cells, respectively).

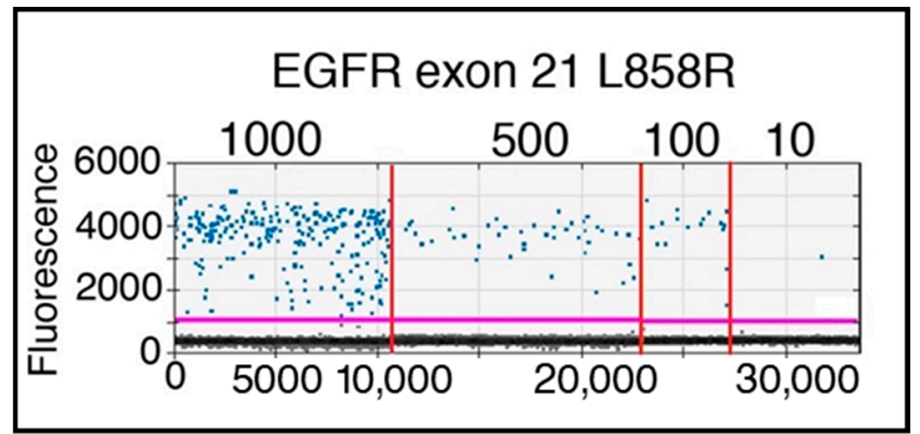

Figure 6. 1-D plot showing ddPCR results of spike-in samples performed with H1975 mutated cell line in healthy donor blood sample. The ordinate scale indicates fluorescence intensity. The magenta line is the fluorescence-threshold, above which droplets (blue) containing EGFR p.L858R mutated copies are present. Serial dilutions, from 1000 to $10 \mathrm{H} 1975$ cells, are separated by the vertical red lines.

\subsection{Harvesting and Molecular Analysis of Hypermetabolic Fraction in NSCLC Patients}

Samples from patients $(n=30)$ affected by metastatic non-small cell lung cancer were stored at room temperature, and processed and analyzed within $6 \mathrm{~h}$. The storage at room temperature did not affect the cell viability, which was measured on a set of healthy donor samples $(n=10)$ after 3 and $6 \mathrm{~h}$, resulting in $94 \% \pm 4$ and $95 \% \pm 3$, respectively. A depletion of $90.2 \pm 4.8 \%$ of CD45(+) cells was achieved in the pre-analytical step using immune-magnetic beads and columns $(n=6)$. Cells presenting the highest uptake of glucose were sorted according to "2.5 SD" threshold (Figure 7). We sorted an average of $4475 \pm 4678$ cells per sample (range 100-17,000).

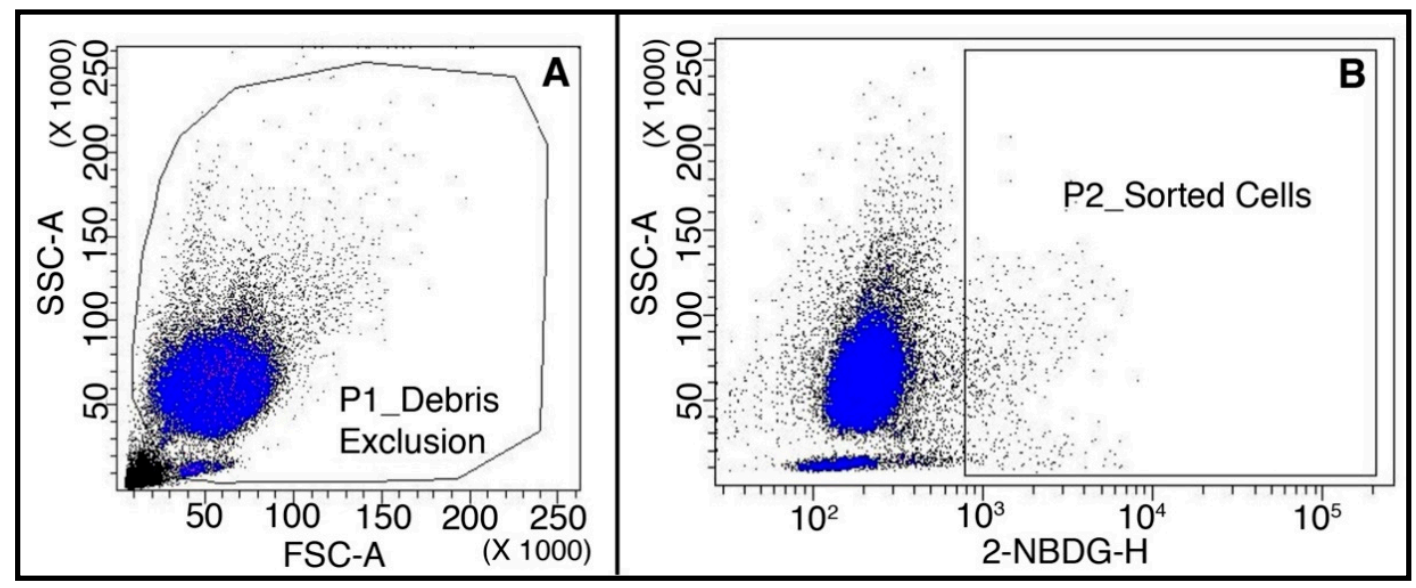

Figure 7. Analysis of a representative patient blood sample. (A) Dot-plot showing the morphological parameters Forward- and Side-Scatters; P1 gate selects cells and discards debris; (B) dot-plot showing the glucose uptake of P1-gated cells; P2 gate selects cells with the highest intensity of 2-NBDG fluorescence according to the " $2.5 \mathrm{SD}$ " threshold.

DNA was extracted from the sorted fraction and ddPCR (Figure 8 and Supplementary Table S2) was adopted, to detect the same mutations found in the primary tumor (with three exceptions, described below). 


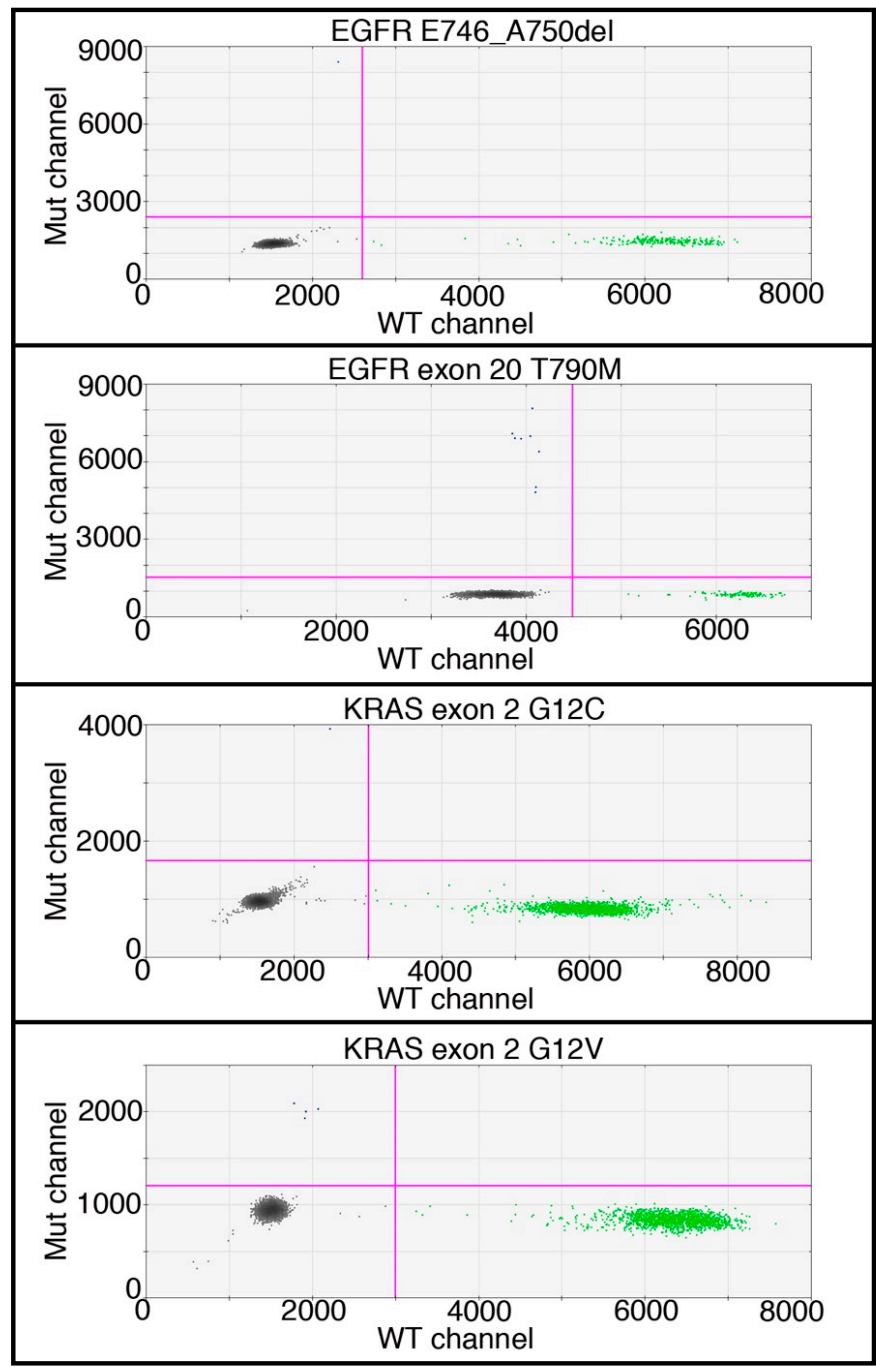

Figure 8. 2-dimensional dot-plots showing the results of ddPCR of four representative patients in which mutated DNA was detected. In $Y$-axis: intensity of FAM dye tagging mutated DNA (Mut channel); in X-axis: intensity of HEX dye tagging wild type DNA (WT channel). Grey droplets are empty, green droplets contain wild type DNA, and blue droplets contain mutated DNA.

Mutant DNA copies were found in $85 \%$ of patients with known mutations on primary tumor $(22 / 26)$ and in $50 \%$ of cases of patients with a wild type primary tumor $(2 / 4)$ (Table 3$)$. Considering the cases in which the primary tumor and the 2-NBDG(high) fraction were tested for the same mutations $(n=23)$, an exact matching was found in $70 \%$ of the cases $(16 / 23)$ (Table 3$)$. In an additional case $(4.3 \%)$, the matching was partial, since the 2-NBDG(high) fraction showed only one of the two mutations of the primary tumor. In two cases $(8.7 \%)$, the 2-NBDG(high) fraction showed different mutations with respect to the primary tumor. Both cases presented the mutation EGFR p.T790M, known to be involved in drug resistance. Only $17 \%$ of the 2-NBDG(high) fraction (4/23) did not show any mutation.

Noteworthy, in the three cases in which it was not possible to evaluate the perfect matching of the mutations of primary tumors and isolated cells, because of the lack of ddPCR probes (patient 4 and patient 27) or an incomplete description of the mutation of the primary tumor (patient 17), the 2-NBDG(high) fraction resulted to harbor mutations on the same gene evaluated on the primary tumors (patient 4 and patient 17) or at least the same mutation that could be analyzed both in the primary tumor and in the sorted cells (patient 27) (Table 3). 
Table 3. Comparison between the mutations found in the primary tumor and in the 2-NBDG(high) sorted fraction. In bold, we highlighted the mutations detected in the cells that were different or additional with respect to those found in the primary tumor.

\begin{tabular}{|c|c|c|c|}
\hline & Primary Tumor & 2-NBDG(high) & Matching \\
\hline PATIENT 1 & KRAS p.G12C & KRAS p.G12C & Perfect \\
\hline PATIENT 2 & KRAS p.G12C & KRAS p.G12C & Perfect \\
\hline PATIENT 3 & KRAS p.G12C & KRAS p.G12C & Perfect \\
\hline PATIENT 4 * & KRAS p.G12D & KRAS p.G12C & n.a. \\
\hline PATIENT 5 & EGFR p.L858R & EGFR p.L858R & Perfect \\
\hline PATIENT 6 & $\begin{array}{l}\text { EGFR p.E746_A750del } \\
\text { and EGFR p.T790M }\end{array}$ & $\begin{array}{l}\text { EGFR p.E746_A750del } \\
\text { and EGFR p.T790M }\end{array}$ & Perfect \\
\hline PATIENT 7 & EGFR p.E746_A750del & EGFR p.E746_A750del & Perfect \\
\hline PATIENT 8 & EGFR p.L858R & EGFR p.L858R & Perfect \\
\hline PATIENT 9 & $\begin{array}{l}\text { EGFR p.L858R and } \\
\text { EGFR p.T790M }\end{array}$ & $\begin{array}{l}\text { EGFR p.Leu858Arg and } \\
\text { EGFR p.T790M }\end{array}$ & Perfect \\
\hline PATIENT 10 & EGFR p.L858R & EGFR p.L858R & Perfect \\
\hline PATIENT 11 & EGFR p.E746_A750del & EGFR p.E746_A750del & Perfect \\
\hline PATIENT 12 & EGFR p.E746_A750del & EGFR p.E746_A750del & Perfect \\
\hline PATIENT 13 & EGFR p.L858R & EGFR p.L858R & Perfect \\
\hline PATIENT 14 & EGFR p.E746_A750del & EGFR p.E746_A750del & Perfect \\
\hline PATIENT 15 & EGFR p.E746_A750del & EGFR p.E746_A750del & Perfect \\
\hline PATIENT 16 & EGFR p.E746_A750del & EGFR p.E746_A750del & Perfect \\
\hline PATIENT $17^{* *}$ & $\begin{array}{l}\text { KRAS exon } 2 \\
\text { [not specified] }\end{array}$ & $\begin{array}{l}\text { KRAS p.G12C } \\
\text { and KRAS p.G12V }\end{array}$ & n.a. \\
\hline PATIENT 18 & EGFR p.E746_A750del & EGFR p.T790M & Different \\
\hline PATIENT 19 & KRAS p.G12C & $\mathrm{WT}$ & NEG \\
\hline PATIENT 20 & KRAS p.G12C & WT & NEG \\
\hline PATIENT 23 & $\begin{array}{c}\text { EGFR p.L858R and } \\
\text { EGFR p.T790M }\end{array}$ & EGFR p.T790M & Partial \\
\hline PATIENT 25 & EGFR p.E746_A750del & EGFR p.T790M & Different \\
\hline PATIENT $26^{* *}$ & KRAS p.G12C & $\begin{array}{l}\text { KRAS p.G12C and } \\
\text { KRAS G12V }\end{array}$ & Additional \\
\hline PATIENT $27^{* * *}$ & $\begin{array}{l}\text { EGFR p.G719C and } \\
\text { EGFR p.T790M }\end{array}$ & EGFR p.T790M & n.a. \\
\hline PATIENT 29 & KRAS p.G12V & WT & Negative \\
\hline PATIENT 30 & KRAS p.G12C & WT & Negative \\
\hline PATIENT 21 & WT & $\mathrm{WT}$ & Perfect \\
\hline PATIENT 22 & WT & EGFR p.E746_A750del & New mutation \\
\hline PATIENT 24 & WT & KRAS p.G12V & New mutation \\
\hline PATIENT 28 & WT & WT & Perfect \\
\hline
\end{tabular}

* Patient 4-Like for the other patients, KRAS p.G12C and p.G12V mutations, but not p.G12D, were tested.t. ** Patient 17-The mutational status of the primary tumor was not available in full detail: only the mutated oncogene, without additional details, was present in the records. ${ }^{* * *}$ Patient 27 -we tested for the EGFR p.T790M mutation, we did not test for EGFR p.G719C. n.a.: not applicable, either due to unavailability of detailed information on primary tumor mutations or unavailability of specific probes.

As a whole, a new mutation was detected in the 2-NBDG(high) fraction of $8 \%$ of the patients with a mutated tumor.

Interestingly, of the four patients with a wild type primary tumor, two showed no mutations, while, among the others, one showed EGFR p.E746_A750del, and the other the KRAS p.G12V mutation. Patients with wild type primary tumor were tested for all mutations, except for the EGFR p.T790M one, because this latter is usually induced by EGFR-inhibitors, not used in these patients.

In order to exclude that the ddPCR could detect false positive events, we tested both the CD45(+) fraction retained in the depletion column $(n=17)$, and a comparable number of cells of the 2-NBDG(low) fraction $(n=12)$; in both fractions we targeted the same mutation tested in the 2-NBDG(high) fraction. Additionally, we evaluated five healthy donor samples for five different mutations, and genomic 
control DNA were used in each reaction. None of CD45(+) fraction, 2-NBDG(low) fraction, and donor samples were positive for the presence of tested mutations.

In conclusion, the 2-NBDG(high) fraction is enriched in tumor cells whose genetic landscape can be analyzed by ddPCR.

\section{Discussion}

This paper is essentially a proof of principle that, using a metabolic assay coupled with a flow-cytometric analysis, it is possible to sort, at least from NSCLC metastatic patients, CTC that can be genetically analyzed by applying ddPCR, an extremely sensitive technique with a limit of detection of $10^{-4}$ [37]. In the present form, therefore, our approach is essentially a simple, quick, and inexpensive strategy that can be utilized in every flow-cytometry facility to enrich sample in CTC taking advantage of their metabolism.

Elevated glucose uptake is a well-established cancer feature exploited in positron-emission tomography. The work of other independent groups, in addition to ours, suggests that the same principle can be exploited for CTC detection [21-23]. The work of Tang et al. confirms the validity of the concept investigating NSCLC pleural effusions, and showing the detection of hypermetabolic CTC in a limited number of peripheral blood samples [22]. Our work was more focused on peripheral blood and strengthened the evidence collected by Tang et al., showing assessment of EGFR and KRAS mutations in 26 patients. At the same time, the implementation in flow cytometry allows higher standardization and wider diffusion, since currently most institutions have access to a flow cytometry facility. Other approaches, requiring customized microfabricated devices, or dedicated and expensive equipment, have the downside of restricting the availability to specialized labs.

We used ddPCR to confirm that the sorted fraction contained cells originating from the tumor. We observed the presence of multiple mutations in two patients (patient 17 and 26), and the presence of mutations different from the ones detected in the primary tumor in four patients (patients 4, 18, 22, and 24). This suggests that the method can probe intra-patient CTC heterogeneity [38,39], which might be important in tracking disease evolution in serial biopsies.

In this proof of concept, we did not enumerate CTC, choosing to pre-amplify target genes in order to prioritize sensitivity of their detection, though preventing in this way accurate quantitation. CTC enumeration would be theoretically possible by determining both absolute mutant copies and mutant allele frequency by ddPCR, without previous targeted amplification.

One of the main advantages of CTC over ctDNA is the possibility to characterize the "omics" of a single viable tumor cell, or generate CTC-based cell lines for studying mechanisms of metastasis. Metastasis is the main mechanism ultimately causing cancer-related death [40], but it is still poorly understood. Enriched CTC, being the actual cells responsible for metastasis formation in vivo, are excellent candidates for such studies. For both aims, it is important that cells do not undergo severe toxicity during the detection process. The fluorescent metabolite used in the present study is a deoxyglucose analog that is not metabolized, potentially depleting intracellular glucose available to cells [41]. Although no short-term toxicity has been described [42], growth-inhibition of cancer cells by NBDG has been reported through increased oxidative stress, interference with $N$-linked glycosylation, and induction of autophagy [43]. For these reasons, we think that the feasibility of culturing the isolated cells for studies, such as clonal expansion, long-term vitality, and drug sensitivity assays, might not be excluded but needs further validation. Some authors indicate that cell culture of isolated CTC might also suffer of shear stress and high voltage pulse during the sorting procedure [44], although culturing of FACS-sorted cells is an established practice in cell biology.

This method is not limited to CTC with epithelial phenotype, or with increased size, like most of methods presented so far. Furthermore, the method focuses on viable, metabolically active cells, while the other methods often include dead or apoptotic CTC, which might not indicate progression of the disease, as such cells are no longer able to metastasize efficiently. 
The presented method could be improved by the addition of CD45 labeling and a double gating on CD45(-), 2-NBDG(high) cancer cells. The antibody labeling on one hand would add cost and complexity to the procedure, but, on the other hand, it would decrease the number of contaminants, potentially enabling sorting of single CTC, which could then be analyzed individually.

Although promising, this is a preliminary study that requires to be validated in an independent case study including a larger number of lung cancer patients. The results can be further strengthened by including both metastatic and non-metastatic patients, since these latter are known to harbor a low number of CTC [12]. Additionally, since in the 2-NBDG(high) fraction of some patients were described mutations not detected in the primary tumor, it would be extremely interesting to add metastasis samples in the mutational analysis. Because metastases are rarely available (this was also our case), the analysis of circulating tumor DNA could represent an alternative.

In conclusion, the presented method has the potential to impact on CTC research field, being a tool for low-cost liquid biopsy with a simple and reproducible procedure.

\section{Materials and Methods}

\subsection{2-NBDG Uptake by White Blood Cells and Cancer Cell Lines}

To exclude that storage at room temperature could affect blood cells, the viability of WBC from 10 healthy donor samples was assessed, after 3 and $6 \mathrm{~h}$ of storage at room temperature, by ADAM-MC automatic cell counter (NanoEnTek, Waltham, MA, USA), according to the manufacturer's protocol.

To evaluate the 2-NBDG (CAS number 186689-07-6; ThermoFisher, Waltham, MA, USA) uptake, white blood cells (WBCs) were obtained from the peripheral blood of healthy donors $(n=3)$, after red blood cell lysis by ammonium chloride; experiments were performed in triplicate. Human cell lines H1975, MDA-MB-231, MCF7, A549, and H460 (ATCC) were grown according to product sheets, using reagents provided by ThermoFisher (media and antibiotics), and EuroClone (Pero (MI), Italy) (fetal bovine serum). Cells were maintained in culture until confluence, and then detached with $1 \%$ trypsin-EDTA (Ethylene-diamine-tetra-acetic acid). The authenticity of the cell lines was assessed by Short Tandem Repeat (STR) DNA profiling (Supplementary Table S3).

WBC and cell lines were incubated separately at $37^{\circ} \mathrm{C}$ for $20 \mathrm{~min}$ with $350 \mu \mathrm{M}$ 2-NBDG, washed twice and resuspended in $100 \mu \mathrm{L}$ of phosphate-buffered saline (PBS) for flow cytometry analysis (FACS Canto II, Becton Dickinson, San Jose, CA, USA). Experiments were performed in triplicate.

\subsection{Spike-in Assay}

Peripheral blood from healthy donors $(n=10)$ was obtained from the Transfusion Medicine of the Academic Hospital of Udine. In order to measure the recovery rate and the accuracy of the method designed for CTC enrichment, known numbers of MDA-MB-231 in a range of 100 to 10,000 were spiked into $250 \mu \mathrm{L}$ of peripheral blood, while H460, H1975, and A549 were spiked-in in the same range number in $1 \mathrm{~mL}$ of peripheral blood to simulate the frequency of rare events. In a set of experiments aimed at evaluating the ability of ddPCR to detect the specific mutation EGFR exon 21 L858R, 10, 100, 500, and $1000 \mathrm{H} 1975$ cells were spiked into $1 \mathrm{~mL}$ of peripheral blood. Tumor cells were labeled with the fluorescent nuclear marker HOECHST 33342 (ThermoFisher) and counted using a Burker's chamber before being spiked into blood donor samples. After red blood cells lysis, 350 M 2-NBDG [2-(N-(7-Nitrobenz-2-oxa-1,3-diazol-4-yl)Amino)-2-Deossiglucose; CAS number 186689-07-6] (ThermoFisher) was added to the sample, which was then incubated at $37^{\circ} \mathrm{C}$ for $20 \mathrm{~min}$. Cells were washed twice and resuspended in $100 \mu \mathrm{L}$ of phosphate-buffered saline (PBS) for flow cytometry analysis.

\subsection{Patient Samples, Healthy Donors and Clinical Data}

The local ethics committee approved the study with protocol number 18387. Written informed consents were obtained from patients and blood donors and all clinical investigations have been 
conducted according to the principles expressed in the Declaration of Helsinki. Sample collection started February 2016. This feasibility trial was conducted within the Institute of Pathology and the Department of Oncology of the Academic Hospital of Udine.

A total of 28 healthy donors were used for this study: $n=3$ for 2-NBDG uptake experiments; $n=10$ to evaluate cell viability upon storage at room temperature; $n=5$ for the detection of five gene mutations by ddPCR and, finally, $n=10$ for spike-in samples (see specific sections for details).

For each patient enrolled $(n=30), 3 \mathrm{~mL}$ of peripheral whole blood were collected into EDTA tubes (BD Vacutainer ${ }^{\circledR}$; BD, Franklin Lakes, NJ, USA). An identification number was assigned to anonymize the samples. All data have been treated according to law and Helsinki criteria.

Inclusion criteria were: 18 years of age or older, diagnosis of NSCLC, Eastern Cooperative Oncology Group (ECOG) performance status between 0-2 without organ dysfunction, presence of metastatic disease confirmed by imaging or pathological analysis, with no discrimination between local $(n=13)$ and distant metastatic sites $(n=17)$. All samples were stored at room temperature and processed within $6 \mathrm{~h}$ from the sample collection to minimize the metabolic variability of cells. The clinico-pathological characteristics of the patients included in the study are summarized in Table 4 .

Table 4. Demographic, clinical, and pathological characteristics of the 30 patients enrolled.

\begin{tabular}{|c|c|}
\hline Characteristic & Years, mean (range) \\
\hline Age & $68(51-87)$ \\
\hline Characteristic & Number of patients ( $\%$ on total) \\
\hline \multicolumn{2}{|l|}{ Gender ( $n$ of patients $(\%)$ ) } \\
\hline Male & $16(53.3 \%)$ \\
\hline Female & $14(46.7 \%)$ \\
\hline \multicolumn{2}{|l|}{ Histological subtype ( $n$ of patients $(\%)$ ) } \\
\hline Adenocarcinoma (ADC) & $29(96.7 \%)$ \\
\hline Unknown & $1(3.3 \%)$ \\
\hline \multicolumn{2}{|l|}{ Mutation ( $n$ of patients $(\%)$ ) } \\
\hline Mutation of the primary tumor: & $26(86.7 \%)$ \\
\hline EGFR & $16(61.5 \%)$ \\
\hline p.E746_A750del & $9(34.6 \%)$ \\
\hline p.L858R & $6(23.1 \%)$ \\
\hline p.T790M & $4(15.4 \%)$ \\
\hline KRAS & $10(38.5 \%)$ \\
\hline p.G12C & $8(30.8 \%)$ \\
\hline p.G12V & $1(3.8 \%)$ \\
\hline Unknown & $1(3.8 \%)$ \\
\hline Wild-type primary tumor & $4(13.3 \%)$ \\
\hline \multicolumn{2}{|c|}{ ECOG Performance Status ( $n$ of patients $(\%)$ ) } \\
\hline 0 & $18(60 \%)$ \\
\hline 1 & $9(30 \%)$ \\
\hline 2 & $2(6.7 \%)$ \\
\hline Unknown & $1(3.3 \%)$ \\
\hline \multicolumn{2}{|l|}{ Stage ( $n$ of patients $(\%)$ ) } \\
\hline IV & $29(96.7 \%)$ \\
\hline Unknown & $1(3.3 \%)$ \\
\hline \multicolumn{2}{|l|}{ Metastatic status ( $n$ of patients $(\%)$ ) } \\
\hline $\mathrm{Mx}$ & $1(3.3 \%)$ \\
\hline M1 & $29(96.7 \%)$ \\
\hline \multicolumn{2}{|l|}{ Metastatic sites ( $n$ of patients $(\%)$ ) } \\
\hline Lung & $21(70 \%)$ \\
\hline Pleural effusion & $11(36.7 \%)$ \\
\hline Lymph nodes & $3(10 \%)$ \\
\hline Bone & $10(33.3 \%)$ \\
\hline CNS & $6(20 \%)$ \\
\hline Adrenal gland & $2(6.7 \%)$ \\
\hline Liver & $3(10 \%)$ \\
\hline Kidney & $1(3.3 \%)$ \\
\hline
\end{tabular}


KRAS and EGFR mutational status on primary tumor was determined by PCR and quantified by Mass Spectrometry (Myriapod ${ }^{\circledR}$ kit; Diatech Pharmacogenetics, Jesi (AN), Italy) or Real-time PCR (Easy ${ }^{\circledR}$ EGFR kit; Diatech Pharmacogenetics) CE-IVD approved assays, according to manufacturer's instructions. The limit of detection of the tests, according to manufacturers, are $5 \%$ and $0.5 \%$, respectively.

\subsection{Patient Sample Preparation and Staining}

Red blood cells were lysed using an ammonium chloride-based lysing reagent (BD Pharm Lyse ${ }^{\mathrm{TM}}$; BD Biosciences, San Jose, CA, USA) according to manufacturer's protocol. Blood samples were depleted of CD45 cells using magnetic micro-beads and LS columns (Miltenyi Biotec, Bergisch Gladbach, Germany), if appropriate (WBC count $>5000$ cells per $\mu \mathrm{L}$ ). Depletion efficiency was assessed by counting a sample before and after depletion with Bürker chamber, in triplicate. Depleted samples were then labeled with 2-NBDG as in spiking assay. For each patient the CD45(+) fraction recovered from the column was used as wild type control of the molecular analysis.

\subsection{Flow Cytometry and Cell Sorting}

Spike-in assays were evaluated using the BD FACS Canto ${ }^{\mathrm{TM}}$ (BD Biosciences) and FACS Aria III ${ }^{\mathrm{TM}}$ (BD Biosciences).

Patient samples were evaluated using the FACS Aria III ${ }^{\mathrm{TM}}$ operated by the FACS DIVA software (BD Biosciences).

The sorting threshold, to define the 2-NBDG(high) population was designed to be operator-independent, standardized, and including at most few thousands of cells, to avoid an excess of contaminants. The threshold was set as follows: data of the first 20,000 blood cells (excluding fragments, and mostly comprising white blood cells) were acquired to assess average intensity (AVGi) of 2-NBDG and standard deviation (SD). Then, the 2-NBDG(high) population was selected as follows:

$$
\text { 2-NBDG(high) if 2-NBDG > AVGi + 2.5 × SD }
$$

In other words, we sorted out the cells with the highest uptake of glucose, exceeding the average white blood cell of 2.5 -fold the standard deviation.

Additionally, a comparable number of 2-NBDG(low) cells was also sorted and further analyzed in 12 patients. This was meant both to prove that the 2-NBDG-dependent sorting was a necessary step to enrich CTC and that the mutated DNA was actually coming from sorted cells, not from cfDNA present in suspension. In fact, cfDNA, if any molecule was left after all washing steps, should have been homogeneously dispersed in the liquid phase, so mutated DNA should have been founded both in the 2-NBDG(high) and the 2-NBDG(low) fraction. If, instead, mutated DNA was actually coming only from hypermetabolic cells, it should have been present only in the 2-NBDG(high) fraction.

\subsection{DNA Mutation Detection}

Genomic DNA isolated from sorted cells after a proteinase K digestion was investigated via ddPCR to prove neoplastic genotype. For patient samples, targeted DNA was pre-amplified using specific primers for EGFR and KRAS (Biorad, Hercules, CA, USA); a single preamplification PCR reaction of 15 cycles was performed for each sample. Although preamplification is not mandatory for ddPCR analysis, considering the variability of the disease, rarity of CTC, and that an estimate number of CTC was not possible for the single patient a priori, for this proof of concept we opted for a light preamplification of target genes, choosing sensitivity in detecting targeted genes over accurate quantification, which was not possible after preamplification. Instead, for spiking assay, where quantification of sorted cells was necessary to evaluate the entire workflow, the preamplification step was by-passed.

Before measuring the mutation levels of targeted genes in patient samples, the preamplification product was diluted 50 times with $\mathrm{ddH}_{2} \mathrm{O}$. The ddPCR mixture was prepared according to 
manufacturer's instructions using the Biorad ddPCR Supermix for Probes (No dUTP) and the specific hybridization probes, conjugated with the dye FAM, for the detection of EGFR p.T790M, p.L858R, and p.E746_A750del and for revealing KRAS mutations p.G12C and p.G12V. The wild type probes both for EGFR and for KRAS were labeled with the dye HEX (ddPCR assay kits, Biorad). All probes were obtained from Biorad, with the following IDs:

$\begin{array}{ll}\text { EGFR: dHsaCP000039 p.E746_A750del } & \text { WT: dHsaCP2000040 } \\ \text { EGFR: dHsaCP000019 p.T790M } & \text { WT: dHsaCP2000020 } \\ \text { EGFR: dHsaCP000021 p.L858R } & \text { WT: dHsaCP2000022 } \\ \text { KRAS: dHsaCP000007 p.G12C } & \text { WT: dHsaCP2500585 } \\ \text { KRAS: dHsaCP2500592 p.G12V } & \text { WT: dHsaCP2500593 }\end{array}$

PCR reagents with the DNA extracted from samples (final volume of $20 \mu \mathrm{L}$ ) and $70 \mu \mathrm{L}$ of oil were loaded into the droplet generator in an 8-well cartridge, in order to generate monodispersed droplets. Then, the emulsion was transferred into a 96-well plate and amplified with a specific thermal profile: $95{ }^{\circ} \mathrm{C}$ for $10 \mathrm{~min}, 40$ cycles of $94{ }^{\circ} \mathrm{C}$ for $30 \mathrm{~s}$, and $56^{\circ} \mathrm{C}$ for $60 \mathrm{~s}$, and a final step at $98^{\circ} \mathrm{C}$ for $10 \mathrm{~min}$. After the amplification protocol, the plate was loaded into the QX100 droplet reader (BioRad).

For each ddPCR reaction a wild type control, a mutant positive control and a no-template-control (no DNA) were set up for the correct determination of the fluorescence threshold. The presence of targeted mutations in patient samples were identified and analyzed using the QuantaSoft software (BioRad).

\subsection{Statistical Analysis}

Data are presented as mean \pm standard deviation or median and interquartile range, as appropriate. Comparison of medians between two groups were performed by Mann-Whitney tests, while Kruskall-Wallis test followed by Dunn's post-test was used to compare more than two groups. To compare cumulative distributions, the nonparametric two sample Kolmogorov-Smirnov test was used. $p<0.05$ was considered significant. Statistical analyses were performed by GraphPad Prism 6 software (GraphPad software, La Jolla, CA, USA).

\section{Conclusions}

In this proof of concept study we demonstrate that CTC can be enriched from NSCLC metastatic patients exploiting their increased glucose uptake via flow cytometry. CTC can then be successfully screened for genetic mutations using ddPCR, revealing both matching and new mutations with respect to the primary tumor analysis. The strength of this method lies in its accessibility to every flow cytometry facility, the relative simplicity of the workflow and the low cost of reagents required. Furthermore, the method is not limited to CTC with epithelial phenotype or increased size, and focuses on viable, metabolically active cancer cells.

Supplementary Materials: The following are available online at http:/ / www.mdpi.com/2072-6694/10/8/270/s1, Table S1: Raw data of spike-in experiments of MDA-MB-231 cells into blood samples; Table S2: Raw data of the ddPCR assays of the 2-NBDG(high) cells, isolated from 30 patients affected by stage IV NSCLC; Table S3: STR analyses of cancer cell lines.

Author Contributions: Conceptualization, M.T., and F.D.B.; Methodology, M.B., F.D.B., and A.Z.; Validation, M.T., G.B., G.F., and D.C.; Formal Analysis, G.B. and F.D.B.; Investigation, M.B.; Resources, G.F., A.S., and C.D.L.; Data Curation, M.B. and E.B.; Writing-Original Draft Preparation, M.T. and F.D.B.; Visualization, M.T. and M.B.; Supervision, M.T., D.C., and F.D.B.; Project Administration, L.M., A.S., and C.D.L.; Funding Acquisition, L.M.

Funding: This research was funded by “Grant AIRC 5 PER MILLE Special Program 2011, grant number 12214: Innovative tools for cancer risk assessment and early diagnosis". The funding source had no role in the conduct of the research; in the preparation of the article; in study design; in the collection, analysis, and interpretation of data; in the writing of the report; in the decision to submit the article for publication.

Acknowledgments: We are grateful to Raffaella Donato and nurses of the Department of Oncology and Cristina Feruglio, Clinical Pathologist at the Academic Hospital of Udine. We are grateful to Alfonso Colombatti for reviewing data and revising the manuscript and to Alan "Tester" Sacilotto for technical assistance. 
Conflicts of Interest: The authors declare no conflicts of interest. The founding sponsors had no role in the design of the study; in the collection, analyses, or interpretation of data; in the writing of the manuscript, and in the decision to publish the results.

\section{References}

1. Ferlay, J.; Soerjomataram, I.; Dikshit, R.; Eser, S.; Mathers, C.; Rebelo, M.; Parkin, D.M.; Forman, D.; Bray, F. Cancer incidence and mortality worldwide: Sources, methods and major patterns in GLOBOCAN 2012. Int. J. Cancer 2015, 136, E359-E386. [CrossRef] [PubMed]

2. Chan, B.A.; Hughes, B.G.M. Targeted therapy for non-small cell lung cancer: Current standards and the promise of the future. Transl. Lung Cancer Res. 2015, 4, 36-54. [CrossRef] [PubMed]

3. Wu, Y.-L.; Sequist, L.V.; Hu, C.-P.; Feng, J.; Lu, S.; Huang, Y.; Li, W.; Hou, M.; Schuler, M.; Mok, T.; et al. EGFR mutation detection in circulating cell-free DNA of lung adenocarcinoma patients: Analysis of LUX-Lung 3 and 6. Br. J. Cancer 2017, 116, 175-185. [CrossRef] [PubMed]

4. Bulfoni, M.; Turetta, M.; Del Ben, F.; Di Loreto, C.; Beltrami, A.; Cesselli, D. Dissecting the Heterogeneity of Circulating Tumor Cells in Metastatic Breast Cancer: Going Far Beyond the Needle in the Haystack. Int. J. Mol. Sci. 2016, 17, 1775. [CrossRef] [PubMed]

5. Cristofanilli, M. Circulating tumor cells, disease progression, and survival in metastatic breast cancer. Semin. Oncol. 2006, 33 (Suppl. 9), 9-14. [CrossRef] [PubMed]

6. Siravegna, G.; Marsoni, S.; Siena, S.; Bardelli, A. Integrating liquid biopsies into the management of cancer. Nat. Rev. Clin. Oncol. 2017, 14, 531-548. [CrossRef] [PubMed]

7. Dawson, S.J.S.-J.; Tsui, D.W.D.W.Y.; Murtaza, M.; Biggs, H.; Rueda, O.M.O.M.; Chin, S.F.S.-F.; Dunning, M.J.M.J.; Gale, D.; Forshew, T.; Mahler-Araujo, B.; et al. Analysis of circulating tumor DNA to monitor metastatic breast cancer. N. Engl. J. Med. 2013, 368, 1199-1209. [CrossRef] [PubMed]

8. Diehl, F.; Schmidt, K.; Choti, M.A.; Romans, K.; Goodman, S.; Li, M.; Thornton, K.; Agrawal, N.; Sokoll, L.; Szabo, S.A.; Kinzler, K.W.; Vogelstein, B.; Diaz, L.A. Circulating mutant DNA to assess tumor dynamics. Nat. Med. 2008, 14, 985-990. [CrossRef] [PubMed]

9. Scher, H.I.; Lu, D.; Schreiber, N.A.; Louw, J.; Graf, R.P.; Vargas, H.A.; Johnson, A.; Jendrisak, A.; Bambury, R.; Danila, D.; et al. Association of AR-V7 on Circulating Tumor Cells as a Treatment-Specific Biomarker With Outcomes and Survival in Castration-Resistant Prostate Cancer. JAMA Oncol. 2016, 2. [CrossRef] [PubMed]

10. Thierry, A.R.; Mouliere, F.; El Messaoudi, S.; Mollevi, C.; Lopez-Crapez, E.; Rolet, F.; Gillet, B.; Gongora, C.; Dechelotte, P.; Robert, B.; et al. Clinical validation of the detection of KRAS and BRAF mutations from circulating tumor DNA. Nat. Med. 2014, 20, 430-435. [CrossRef] [PubMed]

11. Alix-Panabières, C.; Pantel, K. Challenges in circulating tumour cell research. Nat. Rev. Cancer 2014, 14, 623. [CrossRef] [PubMed]

12. Krebs, M.G.; Sloane, R.; Priest, L.; Lancashire, L.; Hou, J.-M.; Greystoke, A.; Ward, T.H.; Ferraldeschi, R.; Hughes, A.; Clack, G.; et al. Evaluation and prognostic significance of circulating tumor cells in patients with non-small-cell lung cancer. J. Clin. Oncol. 2011, 29, 1556-1563. [CrossRef] [PubMed]

13. Marrinucci, D.; Bethel, K.; Kolatkar, A.; Luttgen, M.S.; Malchiodi, M.; Baehring, F.; Voigt, K.; Lazar, D.; Nieva, J.; Bazhenova, L.; et al. Fluid biopsy in patients with metastatic prostate, pancreatic and breast cancers. Phys. Biol. 2012, 9, 016003. [CrossRef] [PubMed]

14. Yu, M.; Bardia, A.; Wittner, B.S.; Stott, S.L.; Smas, M.E.; Ting, D.T.; Isakoff, S.J.; Ciciliano, J.C.; Wells, M.N.; Shah, A.M.; et al. Circulating breast tumor cells exhibit dynamic changes in epithelial and mesenchymal composition. Science 2013, 339, 580-584. [CrossRef] [PubMed]

15. Veridex, L. Veridex CellSearch—Intended Use, Section 3; Menarini Silicon Biosystems: Bologna, Italy, 2008.

16. Marchetti, A.; Del Grammastro, M.; Felicioni, L.; Malatesta, S.; Filice, G.; Centi, I.; De Pas, T.; Santoro, A.; Chella, A.; Brandes, A.A.; et al. Assessment of EGFR mutations in circulating tumor cell preparations from NSCLC patients by next generation sequencing: Toward a real-time liquid biopsy for treatment. PLoS ONE 2014, 9, e103883. [CrossRef] [PubMed]

17. Hanssen, A.; Wagner, J.; Gorges, T.M.; Taenzer, A.; Uzunoglu, F.G.; Driemel, C.; Stoecklein, N.H.; Knoefel, W.T.; Angenendt, S.; Hauch, S.; et al. Characterization of different CTC subpopulations in non-small cell lung cancer. Sci. Rep. 2016, 6, 28010. [CrossRef] [PubMed] 
18. Dorsey, J.F.; Kao, G.D.; MacArthur, K.M.; Ju, M.; Steinmetz, D.; Wileyto, E.P.; Simone, C.B.; Hahn, S.M. Tracking viable circulating tumor cells (CTCs) in the peripheral blood of non-small cell lung cancer (NSCLC) patients undergoing definitive radiation therapy: Pilot study results. Cancer 2015, 121, 139-149. [CrossRef] [PubMed]

19. Nel, I.; Jehn, U.; Gauler, T.; Hoffmann, A.-C. Individual profiling of circulating tumor cell composition in patients with non-small cell lung cancer receiving platinum based treatment. Transl. Lung Cancer Res. 2014, 3, 100-106. [CrossRef] [PubMed]

20. Hanahan, D.; Weinberg, R.A. Hallmarks of cancer: The next generation. Cell 2011, 144, 646-674. [CrossRef] [PubMed]

21. Del Ben, F.; Turetta, M.; Celetti, G.; Piruska, A.; Bulfoni, M.; Cesselli, D.; Huck, W.T.S.; Scoles, G.; Del Ben, F.; Turetta, M.; et al. A Method for Detecting Circulating Tumor Cells Based on the Measurement of Single-Cell Metabolism in Droplet-Based Microfluidics. Angew. Chem. Int. Ed. 2016, 55, 8581-8584. [CrossRef] [PubMed]

22. Tang, Y.; Wang, Z.; Li, Z.; Kim, J.; Deng, Y.; Li, Y.; Heath, J.R.; Wei, W.; Lu, S.; Shi, Q. High-throughput screening of rare metabolically active tumor cells in pleural effusion and peripheral blood of lung cancer patients. Proc. Natl. Acad. Sci. USA 2017, 114, 2544-2549. [CrossRef] [PubMed]

23. Cai, H.; Peng, F. 2-NBDG fluorescence imaging of hypermetabolic circulating tumor cells in mouse xenograft model of breast cancer. J. Fluoresc. 2013, 23, 213-220. [CrossRef] [PubMed]

24. Younes, M.; Lechago, L.V.; Somoano, J.R.; Mosharaf, M.; Lechago, J. Wide expression of the human erythrocyte glucose transporter Glut1 in human cancers. Cancer Res. 1996, 56, 1164-1167. [PubMed]

25. Ooi, A.T.; Gower, A.C.; Zhang, K.X.; Vick, J.L.; Hong, L.; Nagao, B.; Wallace, W.D.; Elashoff, D.A.; Walser, T.C.; Dubinett, S.M.; et al. Molecular profiling of premalignant lesions in lung squamous cell carcinomas identifies mechanisms involved in stepwise carcinogenesis. Cancer Prev. Res. (Philadelphia PA) 2014, 7, 487-495. [CrossRef] [PubMed]

26. Koh, Y.W.; Lee, S.J.; Park, S.Y. Differential expression and prognostic significance of GLUT1 according to histologic type of non-small-cell lung cancer and its association with volume-dependent parameters. Lung Cancer 2017, 104, 31-37. [CrossRef] [PubMed]

27. Tan, Z.; Yang, C.; Zhang, X.; Zheng, P.; Shen, W. Expression of glucose transporter 1 and prognosis in non-small cell lung cancer: A pooled analysis of 1665 patients. Oncotarget 2017, 8, 60954-60961. [CrossRef] [PubMed]

28. Giatromanolaki, A.; Sivridis, E.; Arelaki, S.; Koukourakis, M.I. Expression of enzymes related to glucose metabolism in non-small cell lung cancer and prognosis. Exp. Lung Res. 2017, 43, 167-174. [CrossRef] [PubMed]

29. Meijer, T.W.H.; Schuurbiers, O.C.J.; Kaanders, J.H.A.M.; Looijen-Salamon, M.G.; de Geus-Oei, L.-F.; Verhagen, A.F.T.M.; Lok, J.; van der Heijden, H.F.M.; Rademakers, S.E.; Span, P.N.; et al. Differences in metabolism between adeno- and squamous cell non-small cell lung carcinomas: Spatial distribution and prognostic value of GLUT1 and MCT4. Lung Cancer 2012, 76, 316-323. [CrossRef] [PubMed]

30. Schrevens, L.; Lorent, N.; Dooms, C.; Vansteenkiste, J. The role of PET scan in diagnosis, staging, and management of non-small cell lung cancer. Oncologist 2004, 9, 633-643. [CrossRef] [PubMed]

31. Vansteenkiste, J.F. PET scan in the staging of non-small cell lung cancer. Lung Cancer (Amsterdam Netherlands) 2003, 42 (Suppl. 1), 27-37. [CrossRef]

32. Venturelli, L.; Nappini, S.; Bulfoni, M.; Gianfranceschi, G.; Dal Zilio, S.; Coceano, G.; Del Ben, F.; Turetta, M.; Scoles, G.; Vaccari, L.; et al. Glucose is a key driver for GLUT1-mediated nanoparticles internalization in breast cancer cells. Sci. Rep. 2016, 6, 21629. [CrossRef] [PubMed]

33. Bulfoni, M.; Gerratana, L.; Del Ben, F.; Marzinotto, S.; Sorrentino, M.; Turetta, M.; Scoles, G.; Toffoletto, B.; Isola, M.; Beltrami, C.A.; et al. In patients with metastatic breast cancer the identification of circulating tumor cells in epithelial-to-mesenchymal transition is associated with a poor prognosis. Breast Cancer Res. BCR 2016, 18, 30. [CrossRef] [PubMed]

34. He, W.; Kularatne, S.A.; Kalli, K.R.; Prendergast, F.G.; Amato, R.J.; Klee, G.G.; Hartmann, L.C.; Low, P.S. Quantitation of circulating tumor cells in blood samples from ovarian and prostate cancer patients using tumor-specific fluorescent ligands. Int. J. Cancer 2008, 123, 1968-1973. [CrossRef] [PubMed]

35. Maertens, Y.; Humberg, V.; Erlmeier, F.; Steffens, S.; Steinestel, J.; Bögemann, M.; Schrader, A.J.; Bernemann, C. Comparison of isolation platforms for detection of circulating renal cell carcinoma cells. Oncotarget 2017, 8 , 87710-87717. [CrossRef] [PubMed] 
36. Kallergi, G.; Politaki, E.; Alkahtani, S.; Stournaras, C.; Georgoulias, V. Evaluation of Isolation Methods for Circulating Tumor Cells (CTCs). Cell. Physiol. Biochem. 2016, 40, 411-419. [CrossRef] [PubMed]

37. Droplet Digital ${ }^{\mathrm{TM}}$ PCR Applications Guide. Bio-Rad Laboratories. Available online: http://www.bio-rad. com/webroot/web/pdf/lsr/literature/Bulletin_6407.pdf (accessed on 12 August 2018).

38. Gasch, C.; Bauernhofer, T.; Pichler, M.; Langer-Freitag, S.; Reeh, M.; Seifert, A.M.; Mauermann, O.; Izbicki, J.R.; Pantel, K.; Riethdorf, S. Heterogeneity of Epidermal Growth Factor Receptor Status and Mutations of KRAS/PIK3CA in Circulating Tumor Cells of Patients with Colorectal Cancer. Clin. Chem. 2013, 59, 252-260. [CrossRef] [PubMed]

39. Mostert, B.; Jiang, Y.; Sieuwerts, A.M.; Wang, H.; Bolt-De Vries, J.; Biermann, K.; Kraan, J.; Lalmahomed, Z.; Van Galen, A.; De Weerd, V.; et al. KRAS and BRAF mutation status in circulating colorectal tumor cells and their correlation with primary and metastatic tumor tissue. Int. J. Cancer 2013, 133, 130-141. [CrossRef] [PubMed]

40. Mehlen, P.; Puisieux, A. Metastasis: A question of life or death. Nat. Rev. Cancer 2006, 6, 449-458. [CrossRef] [PubMed]

41. Yoshioka, K.; Saito, M.; Oh, K.-B.; Nemoto, Y.; Matsuoka, H.; Natsume, M.; Abe, H. Intracellular Fate of 2-NBDG, a Fluorescent Probe for Glucose Uptake Activity, in Escherichia coli Cells. Biosci. Biotechnol. Biochem. 1996, 60, 1899-1901. [CrossRef] [PubMed]

42. Hassanein, M.; Weidow, B.; Koehler, E.; Bakane, N.; Garbett, S.; Shyr, Y.; Quaranta, V. Development of high-throughput quantitative assays for glucose uptake in cancer cell lines. Mol. Imaging Biol. MIB Off. Publ. Acad. Mol. Imaging 2011, 13, 840-852. [CrossRef] [PubMed]

43. Zhang, D.; Li, J.; Wang, F.; Hu, J.; Wang, S.; Sun, Y. 2-Deoxy-D-glucose targeting of glucose metabolism in cancer cells as a potential therapy. Cancer Lett. 2014, 355, 176-183. [CrossRef] [PubMed]

44. Li, Q.; Zhang, X.; Peng, Y.; Chai, H.; Xu, Y.; Wei, J.; Ren, X.; Wang, X.; Liu, W.; Chen, M.; et al. Comparison of the sorting efficiency and influence on cell function between the sterile flow cytometry and immunomagnetic bead purification methods. Prep. Biochem. Biotechnol. 2013, 43, 197-206. [CrossRef] [PubMed]

(C) 2018 by the authors. Licensee MDPI, Basel, Switzerland. This article is an open access article distributed under the terms and conditions of the Creative Commons Attribution (CC BY) license (http:/ / creativecommons.org/licenses/by/4.0/). 